boy taking, as a matter of course, a quart bottle of water to bed with him and finishing it before the morning. Therefore a native always runs a greater risk than the European does. The only treatment which I found to be of any use was small doses of buchu and opium freely diluted. This seemed to allay the irritability of the bladder (which was the prominent symptom) better than anything else. The nonparasitic form of hrematuria was always associated with a high temperature. The usual course of a typical case was as follows: First, a rise in temperature ranging from 103 to $105^{\circ}$; this would last for about two hours, by which time the patient had probably gone to bed. Secondly, a severe rigor, lasting perhaps twenty minutes; about an hour after the riger the temperature falls to about $102^{\circ}$ (probably influenced by antipyretics). Thirdly, a feeling of faintness comes on, marked by great pallor; the first quantity of urine which is passed after this will be absolutely black, and is found to contain a large quantity of grumous material, composed of disintegrated blood-cells. At this stage of the disease no actual blood.cells can be discovered by the microscope; but as the patient recovers, and the amount of blood passed is less in quantity, it becomes more like real blood in its appearance, and cells more or less altered can be readily made out. The hremorrhage usually continues for about three days under treatment ; perhaps it would last longer if not treated, but naturally one did not care to try. And then follows, fourthly, the stage of convalescence; the hæmorrhage has ceased, but there is still a temperature of about $102^{\circ}$, which may persist for a month or until the death of the patient. Probably the system, weakened by the great loss of blood, is unable to resist the malarial poison as it otherwise would; for an African fever is generally sudden both in its onset and in its retrocession; the man who has been moaning with pain and delirium, with temperature $106^{\circ}$ one day, will in two days' time be out stalking antelopes. This, however, is not the case after an attack of hæmaturia; recovery is then always very slow and tedious. This disease is common amongst the Europeans, but rare amongst the natives, although they are frequently attacked by ordinary malarial fever. I have heard of another form of hæmaturia in this district (hæmoglobinuria), but as I have not had a case under my care I give no description of it.

Darfield, near Barnsley, Yorks.

\section{TREATMENT OF ULCERATED SCARLET FEVER AND DIPHTHERITIC THROATS BY IRRIGATION.}

BY N. S. Manning, F.R.C.S.,

MEDICAL SUPERINTENDENT OF THE CITY HOSPITAL, BIRMINGHAM.

I HAVE used the following method of treatment in the ulcerated throats of scarlet fever and diphtheria in the Birminghum City Hospital for about two years and a half. The appliances necessary are a small indiarubber bag sy ringe, 4 or $6 \mathrm{oz}_{\text {, }}$, according to the size of the patient, two small basins, and a towel. The medicament used is boric acid dissolved in hot water (about $105^{\circ}$ F.). In order to facilitate the solution of the boric acid, I have a saturated solution in glycerine, prepared by Messrs. P. Harris and Co., Edmundstreet, Birmingham, of which the following are the proportions : Powdered boric acid, four parts; glycerine (sp. gr. 1260), three parts. The glycerine should be heated by steam, and the boric acid (best quality, carefully powdered) stirred in till the solution is perfect. Of this solution, a large tablespoonful is dissolved in about a pint of hot water. The method of procedure is as follows :-Place the patient sitting up, or, if too weak to sit up, place him on his side with his face over the edge of the pillow. Apply the towel round his neck to keep him dry if any water accidentally gets spilled; withdraw the nozzle from the syringe before filling it, and fill with the solution; replace the nozzle, and direct the patient to open his mouth; then put it into the mouth well over the back of the tongue, and forcibly empty the syringe; at the same time receive the water which rushes out of the mouth and nose into the empty basin. In this way the mouth, fauces, pharynx, and in some cases the posterior and anterior nares, are irrigated. The operation is repeated till the parts are washed quite clean. In cases of purulent discharge from the nose or nasal diphtheria, the same procedure is applied to the nostrils. The irrigation may be performed every two or four hours as circumstances require. In this hospital during two years over 1500 cases of ulcerated scarlet fever and diphtheritic throats have been treated by this method. From this experience $I$ can recommend it as superior to any other I have ever tried. I believe its efficacy is due to the fact that it is founded on the rational principle of washing away all septic discharges with a non-irritating, nonpoisonous fluid. It is not in any way disagreeable to patients ; on the contrary, when the mouth is dry or foul, it is most comforting. The solution is rendered sweet by the glycerine, so that only a small percentage of even very young children offer any objection to it. Occasionally children swallow some, but without any subsequent il effects. It should be borne in mind that, in order to prevent any septic matter being sucked into the syringe, the nozzle should always be withdrawn when filling.

Birmingham.

\section{A CASE OF AINHUM}

By GoRdon MEssum, M.R.C.S., L.R.C.P. LoND., CONSULTING MEDICAL OFFICER TO THE VOLKS' HOSPITAL, AND DISTRICS SURGEON OF PRETORIA.

THIS complaint is commonly met with amongst the natives (Kaffirs) of South Africa, especially in Northern Transvaal, and is usually limited to the little toe; both feet are, however, generally attacked, though not simultaneously. The toe at its junction with the foot has the appearance of being gradually cut off by means of the continuous pressure of a ligature tied round the toe at that spot. The following is an example, extracted from my note-book, of the usual history attached to such cases.

Tozini, aged thirty-four, married. The little toe of his left foot is already gone. About a year ago the dorsum and outer side of his right foot swelled up to a considerable extent and gave him much pain of a burning character, the pain running down into the little toe. The swelling gra. dually subsided, leaving a small pustule on the inner and dorsal aspect of the metatarso-phalangeal joint of the little toe. This pustule, on evacuating the matter, assumed the appearance of a crack, which slowly extended round the toe, eating deeper and deeper through the tissues; all feel. ing gradually left the toe, though the foot remained very painful until the toe dropped off (or in some cases gets accidentally knocked off). The wound quickly healed and gave no more discomfort. The complaint appears to be one of nerve origin, and differs entirely from the "mutilans" form of leprosy. The only cure consists in amputating the toe. Pretoria, S.A. Republic.

\section{dy \\ OP}

\section{HOS PITAL PRACTICE, BRITISH AND FOREIGN.}

Nulla autem est alia pro certo noscendi via, nisi quamplurimas et mor borum et dissectionum historias, tum aliorum tum proprias collectas habere, et inter se comparare.-MoraAGN De Sed. et Catus. Moro., lib. iv. Procemium.

\section{MIDDLESEX HOSPITAL.}

CASES OF INJURIES OF PERIPHERAL NERVES (continued). (Under the care of Mr. HuLkE.)

WE continue below the interesting series of injuries to peripheral nerves which we commenced at page 877 of our last issue. The cases already brought forward include two of wound of the ulnar nerve, one of recovery of function after immediate suture of median, and one of division of the sciatic nerve within its sheath followed by very incomplete recovery of function.

In Case 5 the presence of small sensitive islands in the palm was singular, in presence of the fact that the divided ends of both median and ulnar nerves were separated by not inconsiderable intervals. The relatively early return of sensibility in the palmar distribution of the median nerve after suture, although the ends of this could not be brought into contact, imperfect as it was, and transitory as it proved in some branches, is a remarkable circumstance. In Case 6 , the position of the smaller and posterior of the two scars in 
the ham, taken in connexion with the distinct gap in the tendon of the biceps, plainly told of a tenotomy of this muscle; whilst the condition of the parts supplied by the branches of the external popliteal nerve was strongly suggestive of the accidental simultaneous division of this nerve. Were this so, the louger scar might probably mark the incision for a subsequent suture of the nerve, the final result of which left much to be desired. In this case the scars about the hip unquestionably marked excision of the upper end of the femur, probably with removal of portions of the os innominatum. In Case 7, a gunshot injury, it must remain uncertain whether the nerve was severed by the bullet or by a splinter of bone, or was compressed by an excess of callus. The completeness of loss of function made the former more probable. At the late date of the patient's entry into the Middlesex Hospital little expectation could be entertained of benefit from nerve suture, even had the patient been willing to allow it to be attempted. Case 8 exemplifies nerve irritation from interference by a fragment in a case of comminuted fracture. Case 9 is an instance of trophic lesions consequent on implication of nerve fibrils or a scar. It is suggested, as advocated by Mr. M. Baker, that for whitlows of the terminal phalanx a lateral incision is preferable to a median incision in the pulp of the finger. Instances of this are not very infrequent.

CASE 5. Late suture of the median and ulnar nerves very imperfect restoration of sensibility, and this in some branches transitory.-On Oct. $22 \mathrm{nd}, 1888, \mathrm{E} . \mathrm{C}-$ - aged twenty-three years, a general servant, was admitted into Bird ward for the effects of an injury of the right forearm sustained six months previously. Crossing the anterior surface of the forearm from near the radial styloid process obliquely inwards and upwards to the inner border of the forearm was a scar, which apparently implicated all the structures down to the bones. The muscles forming the ball of the thumb were wasted, as were also all the interossei. The thumb and all the fingers were flexed and rigidly con tractured. Separation and closure and flexion and extension of the fingers were lost. The scar was tender. The small triangular area of the forearm between the scar and the wrist, the palm, and three small oval areas continuous with the palm in the clefts between the four fingers retained a slight degree of sensibility; the patient was conscious when touched with a needle within the limits indicated, but she could not localise with any precision the part touched. The palmar surface of the two phalanges of the thumb and that of all the fingers, excepting the ulnar half of the little finger, and that of the dorsal surface of the terminal and middle phalanges of the three outer fingers, was devoid of sensibility to touch and to stimuli with hot and cold substances. Dr. Pasteur, at that time in charge of the electrical department, found that all the muscles on the distal side of the scar did not respond either to faradaic or to galvanic stimulation. She stated that the scar was the result of a gash occasioned (six ?) months previously by the accidental breaking of a pane of glass at East London in the Cape of Good Hope. A local doctor closed the wound with silver wire sutures and sent her into a hospital, where a week later the stitches were removed. Two days after this bleeding recurred, and having recurred on the following two days the wound was reopened and the ressels were tied. In consequence of this she was in bed during a month. Her band remained useless. Galvanism and massage proving useless she was sent back to England, and two days after landing entered the Middlesex Hospital. On $0 \mathrm{ct}$. 30 th the trunk of the ulnar nerve was exposed; it was found to have been divided a short distance below where it gives off its dorsal digital branch. The interval between the two ends of the nerve (about three-quarters of an inch) was bridged by a slender band of connective tissue; the proximal end was distinctly bulbous and the distal tapering. The trunk of the median nerve was less readily found. The upper bulbously swollen rend had retracted to a much greater extent than had that of the ulnar nerve. A cicatricial band passing distally from it divided near the wrist, one slip being attached to the tendon of the flexor carpi radialis, and the other slip connected with the distal end of the nerve, very close to the anterior annular ligament. The interval between the two ends of the severed nerve was estimated to be two inches. The altered ends of each nerve having been removed, the sectional surfaces of the ulnar were brought in to close conwact by sutures passed through the nerve itself, other suture taking up the eonnective sheath of the nerve only proving in sufficient to withstand the strain. Actual coaptation of the ends of the median nerve was impracticable, an interval of quarter of an inch remained after stretching the proximal part of the trunk, and bringing up the distal end by strong flexion of the hand. Strict antiseptic precautions were observed at the operation and in the subsequent dressings. On Nov. 9th the dorsal surfaces of the terminal and middle phalanges of the two middle fingers were found slightly sensitive to tactile stimuli, and the sensitiveness of this surface of the thumb, which had previously seemed blunted, was increased. Sensitiveness, previously limited to the ulnar half of the palmar surface of the little finger, was now verified for the whole of this surface of this finger. On Nov. 10th the palmar surfaces of the second, third, and fourth fingers, were found sensitive to the touch of a needle. On Nov. 15th the palmar surface of the index finger was found sensitive, and on the 19th it was noted that the sensitiveness of all the parts of the finger and thumb previously insensible had become well marked. Later this sensitıveness to a tactile stimulus diminished. Sensitiveness to the contact of hot and cold objects never returned. On one occasion she scorched her finger-tips whilst toasting a piece of bread. The operation incisions healed slowly, and a small superficial granulating part remained open when, on Feb. 26th, 1889, repeated insubordination made it obligatory on her to leave the hospital. Massage and electrical treatment had proved useless. The fingers then had the tapering, smooth, glossy bluish-red appearance characteristic of the trophic impairment following nerve injuries. The patient subsequently entered St. Thomas's Hospital under Mr. Croft. It is greatly to be regretted that in this case the severed nerves and also the tendons were not each securely united by sutures by the person who saw the recent wound and closed it ; but the place where the accident occurred and the other attendant circumstances must be accepted as extenuating this grave omission. Doubtless also the secondary repeated hremorrhages were adverse to the union of the nerve ends, which may take place even in the absence of suturing. As we are as yet unable to fix in any particular case a term after which union of nerve and restoration of function are impossible, it seemed right to attempt the union of thenerve ends, notwithstanding theadvanced trophic disturbance present when the patient entered the Middlesex Hospital. The return of sensitiveness to touch in the parts before insensible to this stimulus, ascertained first on the tenth day after the operation, and subsequently verified by frequent testing, is a remarkable circumstance in connexion with the fact that the ends of the divided median nerve could not be brought together, but an interval of a quarter of an inch remained between them. It had been intended to intercalate a piece of a living nerve, and an animal was at hand for this purpose, but an unexpected difficulty happened at the last moment, and this design had to be abandoned. Other noteworthy circumstances were the presence of three small sensitive islands at the palmar ends of the digital clefts, and of the anæsthetic areas on the dorsal surfaces of the fingers in the distribution of the radial nerve not itself implicated in the injury. A satis. factory explanation of these seeming anomalies cannot be offered.

CASE 6. Division of the external popliteal nerve whilst dividing the tendon of the biceps; suture; imperfect restoration of sensation only. - B. M-, aged nineteen, seamstress, was admitted in to the hospital on April 4th, 1889. The right lower limb was seven inches and a half shorter than the left; of this shortening five inches represented the disparity of the thighs. All the parts of the right limb were ill.developed in comparison with the corresponding parts of the left; the muscles were limp and flabby. When standing the outline of the limb was obviously curved, the concavity looking forwards, the summit of the curve being at the knee. The foot presented the deformity characteristic of equino-varus. There were extensive scars about the hip. One of these extended from below the middle of Poupart's ligament round the inner side of the thigh to its posterior surface, and another reached from the tuber ischii to the situation of the great trochanter, and thence four inches down the thigh. Another scar nearly two inches long was present over the outer hamstring, two inches above the lowest point of the femoral condyle, and behind this was a fourth smaller scar. All these scars had the distinctive characters of those of surgical incisions. A palpable gap was present in the bicipital tendon corresponding to these lower scars. 
All the muscles innervated by the external popliteal nerve were completely functionless, and the sensibility of the cutaneous area supplied from this trunk was very markedly impaired. The patient stated that she was supposed to have hurt her hip when six years old by falling out of a carriage. One year afterwards she entered a hospital with hip disease, where, in the course of two years, she underwent several operations.

CASE 7. Paralysis of the musculo spiral nerve resulting from a bullet wound.-L. $\mathrm{N}-$, aged twenty-nine, a strong hale man, a French polisher, formerly soldier, was admitted into Founder ward on May 17th, 1890, for the results of an injury to his right arm, received, he said, at the battle of Tel-el-Kebir. At the date of this note the marks of the injury were-a small, depressed scar on the front of the arm, three inches below the shoulder; a larger, rayed scar at the middle of the back of the arm, having close to it the opening of a small sinus, from which a small quantity of serum could be pressed; obvious irregularity and thickening of the humerus between these scars; evident wasting of the extensor muscles on the back of the forearm, with wrist-drop; slightly impaired tactile sensibility of the surface along the radial border of the forearm and the posterior surface of the thumb and forefinger; slightly diminished range of flexion of forearm on arm, and distinct weakness of grasping power of the right hand.

The following memorandum on the electric reactions was written by Dr. Wynter:- "The extensor muscles of the right forearm exhibit complete absence of irritability to the faradaic and the galvanic current, indicating complete wasting of the nerve ends and trunk, the stage of pro gressive degeneration being passed. There is considerable wasting of this group of muscles. The flexors appear to be in a normal condition, as electrically compared with those of the other forearm." The patient stated that at Tel-elKebir he was shot through the arm; the bone was broken. An abscess formed in the wound and burst three weeks later whilst on his voyage to England. At Haslar Hospital the fracture which had united was rebroken and reset, the bone being found in a faulty position. His impression was that the wrist-drop instantly followed the injury. Early in May, 1890, an abscess again formed in the site of injury leaving the existing sinus at the back of the arm as its sequel. Whilst the symptoms were conclusive as to the occurrence of an injury to the trunk of the musculo-spiral nerve the history was not sufficiently precise to warrant a positive opinion as to whether the lesion was the immediate severance of the nerve by the bullet or by splinters of the broken humerus driven before it; or if it was the compression of the nerve by the displaced ends of the broken bone or by callus. To the patient's impression that his wrist-drop dated from the moment of the injury little value could be attached, since it was judged improbable that he could, under the circumstances of the moment, have correctly distinguished between the dropping of his whole arm when the humerus was broken, and the dropping of the wrist apart from this. In the presence of the advanced atrophy of the peripheral branches of the nerve and of the extensors, little benefit was expected from an attempt to reunite the ends of the severed trunk or to extricate it from compression. This, as a tentative measure involving little risk, appeared justifiable, but the patient would not allow it; nor would he permit the exploration of the sinus, though the occurrance of this suggested the presence of a sequestrum, or perhaps a splash of lead. $\mathrm{He}$ soon left the hospital, and his subsequent history is not known.

CASE 8. Irritation of the median nerve by the displaced fragment of a comminuted radius; extrication of nerve; good result.-M. C-_, aged fifty, a hale-looking country woman, whose raven hair was slightly streaked with grey, was admitted into the Middlesex Hospital on Feb. 1st, 1883, for a sequel of an injury to her forearm sustained four months previously by a fall in which she struck this forearm against the edge of a stair. The radiug and ulna had been broken in their lower third, and ine former comminuted. Good union, with slight angular deviation of the axis of the bone, had occurred; but a detached piece of the radius, about half an inch wide and somewhat longer, projected so strongly at the flexor side as to press upon and raise the integument. Here and for some distance around it there were great tenderness and pain, and severe pain was felt also in the palmar surface of the two middle fingers. She said that the pain was so intense that it made her quite unable to use the limb, and it prevented her working.
On Feb. 3rd the projecting piece of bone was laid bare and cut away. It had pushed the median nerve-which was found resting in a groove in the outer border of the frag ment-out of its normal course. A fortnight later she returned home. The wound had very nearly healed. The pain had ceased.

CASE 9. Painful scar of an incision into a whitlow; wasting of finger; amputation.-E. S-, aged twentyone, an anæemic brunette, a cook, was admitted into Bird ward on March 16th, 1887, for a painful state of the middle finger of the left hand, which prevented her working the pain being sometimes so acute as to oblige her to drop whatever she held in this hand at the moment. Nearly in the long axis of the palmar surface of the terminal phalanx of this finger was the depressed scar of an incision made for a whitlow eighteen months previously. This phalanx was shrunken, tapering markedly in figure; its skin smooth, glossy, and red ; and its temperature $0.50^{\circ} \mathrm{F}$. lower than that of the other fingers. The middle phalanx was affected similarly, but in a less degree. The pain, she said never ceased, and it was increased by cold. Topical sedatives, electricity, massage, and tonics had been tried without benefit. Under these circumstances the finger was amputated, and the woman soon left the hospital perfectly relieved.

\section{LEEDS GENERAL INFIRMARY.}

A CASE OF POLYPOID GROWTHS IN THE KNEL JOINT; REMOVAL.

(Under the care of Mr. A. W. Mayo Robson.)

THIs case is of interest not only on account of the rapid recovery following such an extensive operation in the interior of the knee-joint, but because of the unusual nature of the disease for which operation was performed. The tumours seemed to be genuine fibroid polypi arising from the deeper layer of the synovial membrane, and not the ordinary hypertrophied fringes, which may become peduncalated, but which are seldom seen to attain so large a size. For the account of this case we are indebted to Mr. Basil Hall, house surgeon,

J. R-, aged thirty-ejght, a sailor, was admitted on Oct. 27 th, 1890 , with the right knee-joint greatly distended

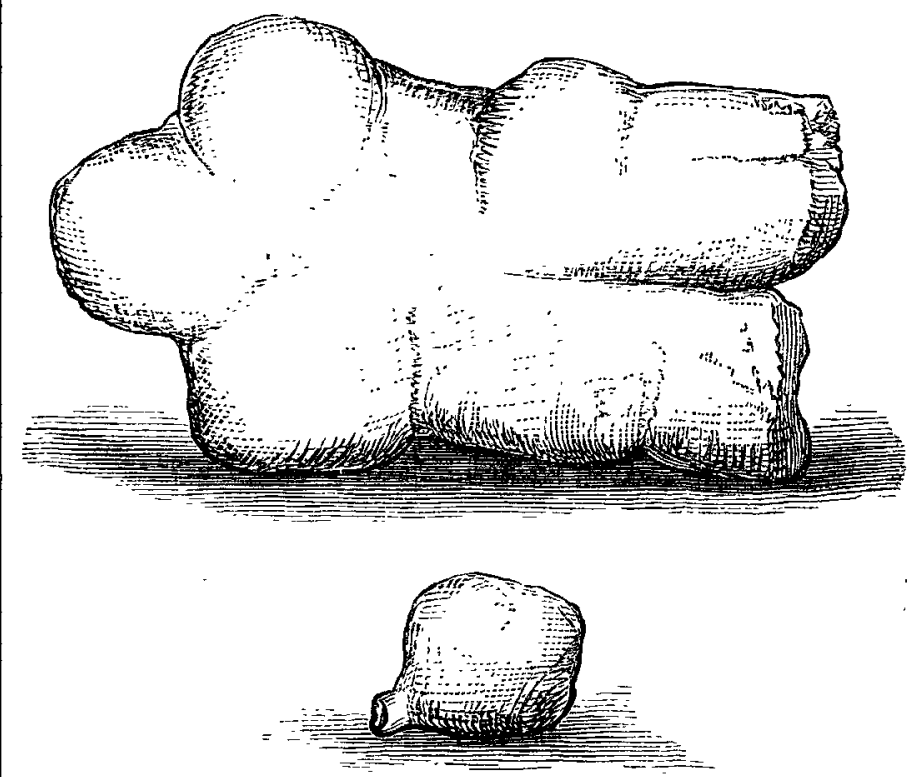

From inner incision.

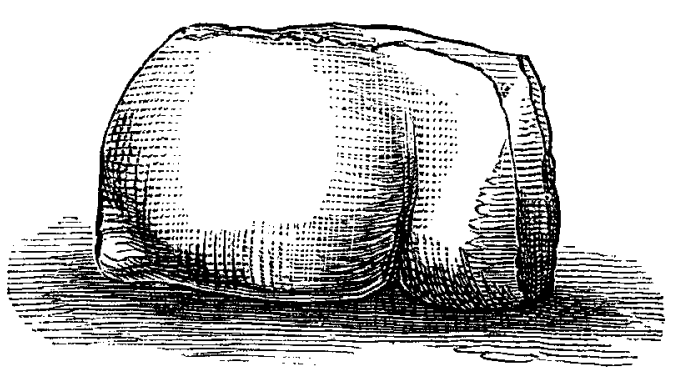

From outer incision.

with fluid. The history was that the knee was struck two years previously by a heavy piece of timber. He remained in bed, and was treated for sixteen weeks, after which he 